\title{
O PARADOXO SOCRÁTICO: A IDEIA DE SABER QUE NADA SE SABE
}

\author{
Homero Damo ${ }^{1}$ \\ Universidade Federal de Santa Maria (UFSM) \\ (iD) https://orcid.org/0000-0003-0911-5819
}

\begin{abstract}
RESUMO:
O presente artigo tem como objetivo analisar o problema epistemológico do paradoxo socrático. Em uma primeira parte do trabalho, apresentaremos o problema segundo Brickhouse and Smith, após a apresentação do problema, em seguida apresentaremos uma objeção feita sobre a honestidade de Sócrates e como uma possível desonestidade resolveria o problema facilmente. Após isso, trabalharemos a divisão entre dois tipos de conhecimento onde um torna seu possuidor um sábio e outro não. Ainda, ao longo do trabalho, estudaremos as três vias principais de obtenção de conhecimento para Sócrates: divinatória, senso comum e elenchos. Apresentaremos também uma explicação sobre o artigo Individualism and the mental, de Tyler Burge onde apresentaremos um experimento mental descrito pelo autor para demonstrar a formação não insular de conceitos e a ideia proposta por ele sobre o entendimento incompleto. Feito isso, ao final, apresentaremos uma proposta alternativa e complementar a teoria de Brickhouse and Smith para a resolução desse aparente paradoxo.
\end{abstract}

PALAVRAS-CHAVE: Sócrates; Paradoxo; Epistemologia; Brickhouse and Smith; Tyler Burge.

\section{THE SOCRATIC PARADOX: THE IDEA KNOW OF KNOWING NOTHING}

\begin{abstract}
:
The present article have the objective of analyzing the epistemological problem of the Socratic paradox. In the first step of this work we will present the problem from a Brickhouse and Smith point of view. After that, we will present an objection done about Socrates telling the truth or telling lies about the knowledge, which is one solution to the problem. After that, we will work in the division of two kind of knowledge where one kind

\footnotetext{
${ }^{1}$ Mestrando em Filosofia na Universidade Federal de Santa Maria (UFSM), Rio Grande do
} Sul - Brasil. E-mail: homerodamo@ hotmail.com
\end{abstract}


makes the people wise, and one not. Therefore, we will be studying 3 ways of getting knowledge: divinatory, common sense and elenchos. We will present as well an explanation about an article called "Individualism and the mental" from Tyler Burge we will present a mental experiment described by him to demonstrate the non insular formation of concepts and the idea proposed by him about not knowing the complete concept. After that, in the end, we will present an alternative and complementary idea about Brickhouse and Smith theory to resolve the problem.

KEYWORDS: Socrates; Paradox; Epistemology; Brickhouse and Smith; Tyler Burge.

\section{Introdução}

Sócrates, sem dúvida, é uma das figuras mais enigmáticas da história da filosofia. Os mistérios por trás do nome Sócrates são muitos e atravessaram os séculos sem solução. Seria Sócrates uma pessoa real? Seria ele o maior personagem de Platão? Porque ele nunca escreveu nada? Seria ele o homem mais sábio entre os gregos?

Dentre as muitas perguntas que estão por trás dessa figura tão singular e enigmática está uma pergunta muito importante: O que Sócrates quer dizer quando diz que não sabe? Como pode ele afirmar que não sabe de nada mas ao mesmo tempo conseguir refutar todos aqueles que diziam saber? A essa afirmação de negação do conhecimento, deu-se o nome de "Paradoxo Socrático". E esse paradoxo, a ideia de afirmar que sabe que não sabe, é o tema central de nossa investigação do presente artigo.

Primeiramente, investigaremos no artigo a opinião de Brickhouse and Smith sobre o paradoxo da ignorância Socrática. Nessa parte do trabalho, nos esforçaremos para demonstrar o que é esse paradoxo, passando pela ideia da aparentemente inconsistência da posição Socrática em seus diálogos e o que significa dizer que sabe que não sabe.

Em seguida, investigaremos uma objeção feita por críticos da filosofia Socrática onde é posto em cheque a honestidade de Sócrates quando ele proferia a frase que sabia que não sabia. Será visto nessa parte duas vias interpretativas, uma que defende que Sócrates é honesto ao proferir a ignorância e outra que diz que ele não é sincero. Veremos nessa parte que se ele de fato não for sincero o paradoxo se resolve de uma maneira bem simples, mas essa não é a opinião de Brickhouse and Smith.

Posto isso, veremos a distinção proposta por Brickhouse and Smith sobre os tipos de conhecimento, um que torna o seu possuidor sábio e outro que não. Veremos como a partir dessa divisão entre tipos de conhecimento podemos resolver o aparente paradoxo. Após essa diferenciação sobre os tipos de conhecimento entraremos em uma outra parte do artigo onde 
investigaremos três tipos de meios para a obtenção de conhecimento: a via divinatória, a via do senso comum, e os elenchos.

Depois de terminada a explicação da teoria de Brickhouse and Smith sobre esse paradoxo, apresentaremos uma outra interpretação do problema, escorada pelo artigo "Individualism and the Mental" de Tyler Burge. Nesse artigo do livro "Foundations of mind" é feito uma investigação filosófica sobre como surge o significado dos termos, onde é feita uma critica ao modelo insular de conhecimento. Demonstraremos que esse artigo de Burge versa sobre um experimento mental em três passos, que leva a uma conclusão fundamental para a nossa investigação. Essa conclusão de Burge (a ideia de entendimento incompleto) é fundamental para apresentarmos através dela uma interpretação alternativa para uma resposta ao paradoxo Socrático.

\section{O paradoxo da ignorância Socrática}

O paradoxo socrático é um problema de origem epistêmica, que curiosamente não foi aparentemente, percebido por seus interlocutores nos diálogos. Em vários diálogos, Sócrates apresenta uma posição aparentemente inconsistente, essa inconsistência é formada pela afirmação de duas ideias que parecem ser contraditórias.

A primeira ideia é que Sócrates afirma nada saber, ou seja, se coloca na posição de ignorante sobre assuntos fundamentais, afirma desconhecer as virtudes. Essa posição, de aporexia em relação ao conhecimento, sozinha não apresenta nenhum problema contraditório grave. Entretanto, ao mesmo tempo, Sócrates demonstra uma quantidade grande de conhecimento, esses usados para descontruir as teses daqueles que julgam conhecer a natureza das virtudes.

Como pode alguém que diz não saber o que é " $A$ " ser capaz de dizer que um "B" não é "A"? Teoricamente, se um indivíduo não conhece o "A" é impossível que ele diga que o "B" não é esse "A", uma vez que ele não vai ter como comparar. Mesmo que o individuo saiba o significado de "B", se ele desconhece o "A" ele jamais poderia dizer que o "B" não é o " $A$ ". Isso demonstra que é necessário, para refutar uma algo, ser capaz de conhecer de algum modo as duas ideias em questão.

Como é possível sustentar a ideia de que alguém que nada sabe pode refutar tantas teses? Será que Sócrates foi incoerente com as suas ideias? Será que esse aparente paradoxo não seria uma interpretação errada dos diálogos? Será que Platão errou ao colocar Sócrates em uma posição tão inconsistente?

Segundo a interpretação de Brickhouse and Smith esse aparentemente paradoxo não existe, é somente uma interpretação errada sobre os tipos de conhecimento proferido por Sócrates em seus diálogos, segundo eles: "Sócrates considera que há dois tipos gerais de conhecimento, 
um que faz o seu possuidor sábio e outro que não." (Brickhouse and Smith, 1994 , p. 31 $)^{2}$. Essa distinção entre os dois tipos de conhecimento anularia esse aparente paradoxo. Para compreendermos essa ideia comecemos primeiro entendendo o que Sócrates queria dizer quando dizia que nada sabia.

\section{Sócrates é sincero ao afirmar que nada sabe?}

Existem duas vias interpretativas a respeito de o que Sócrates quer dizer com o fato de não saber. A primeira via interpretativa é que Sócrates não seria sincero, e essa interpretação por si só já resolveria o paradoxo. Se Sócrates não é sincero ao afirmar que não sabe, então ele saberia das coisas e ocultaria isso dos adversários. Assim, poderíamos responder como Sócrates é capaz de refutar as proposições dos adversários. Ora, se ele sabe o que são as virtudes pode ele então dizer aos adversários com facilidade porque eles estão errados. A ideia de não saber das coisas seria nada mais que uma ironia por parte de Sócrates? Quem sabe.

Entretanto, estudiosos do assunto, como Brickhouse and Smith, rejeitam essa ideia uma vez que ela colocaria outras asserções de Sócrates em cheque. Se ele está mentindo que não sabe, em que outras proposições ditas por ele nós deveríamos confiar?

Brickhouse and Smith, acreditam que Sócrates é sincero ao dizer que nada sabe. Mas como isso é possível? O que Sócrates então quer dizer ao se declarar ignorante? Brickhouse and Smith defendem que para Sócrates existem dois tipos de conhecimento - um que torna o seu possuidor um sábio e outro que não. Segundo os autores a ignorância socrática é explicada do seguinte modo:

Sócrates se permite dizer (em 20d6-9) que ele tem algum tipo de sabedoria, que ele a chama de "sabedoria humana". Mas suas investigações sobre o significado do oráculo mostram-lhe que "A sabedoria humana tem pouco ou nenhum valor" (23a67). O que seria de grande valor, se ele tivesse - nomeadamente a sabedoria real - falta a Sócrates e a todos os outros. A maior sabedoria para todos os humanos, como nós acabamos de ver, é o reconhecimento de que "em verdade nada vale em respeito ao conhecimento" (23b3-4). Ao contrário dos seres humanos "O Deus possui a sabedoria real" (23a5-6). (BRICKHOUSE AND SMITH, 1994, p.33).

O que Sócrates então quer dizer ao proferir que sabe e ao mesmo tempo não sabe? Segundo a interpretação de Brickhouse and Smith, para Sócrates existem dois tipos de conhecimento. O primeiro é o conhecimento

\footnotetext{
${ }^{2}$ Todas as traduções usadas no artigo inteiro são traduções nossas. Essa informação não aparece ao fim de cada citação para que não fique repetitivo demais.
} 
que os humanos têm acesso, que é de pouco ou nenhum valor. $\mathrm{O}$ segundo conhecimento é o conhecimento que os deuses têm acesso, que é o único conhecimento real. O conhecimento que os humanos possuem é um conhecimento que não torna ninguém sábio, e por isso Sócrates afirma não ser um. Mesmo sabendo muitas coisas humanas ele sabe que o conhecimento que ele possui não é nada perto do conhecimento possuído pelos Deuses. E esse conhecimento dos deuses, é o que torna alguém sábio de verdade.

Sócrates foi o homem mais sábio de sua época porque compreendeu isso e através dessa compreensão afirmou a sua ignorância. Essa afirmação de ignorância, é o mais próximo que um homem pode chegar de uma real virtude e por isso, todos aqueles que afirmam virtudes (conhecimento do belo e do bom) podem ser vítimas dos elenchos Socráticos. Ele, o real sábio, sabe que não há real sabedoria entre os homens, somente entre os Deuses, e por isso ao afirmar que nada sabe é um homem muito sábio.

A resolução desse paradoxo então por Brickhouse and Smith se dá pela divisão dos conhecimentos entre dois: um que torna o seu possuidor sábio, que é o conhecimento que nenhum homem pode possuir. E outro que não torna ninguém sábio que é o conhecimento que os homens possuem.

Ainda, é preciso esclarecer que Sócrates não nega o conhecimento, ele mesmo afirma ter conhecimento sobre variadas técnicas. O que Sócrates afirma é não ter o conhecimento das virtudes. Ele não seria, portanto um cético uma vez que alguns conhecimentos ele de fato possui, segundo Brickhouse and Smith como, por exemplo, a definição de rapidez (Laq. 192a) e de figura (Menon 76a). Entretanto esses conhecimentos não são sobre coisas consideradas realmente importantes para Sócrates. Para Sócrates é muito mais importante o conhecimento das virtudes.

Além disso, não se vê uma grande problematização por parte de Sócrates sobre assuntos que possuem um status epistemológico muito controverso, como evidencia dos sentidos, objetos teóricos, teorias científicas, deduções etc. Ele nunca declara ignorância sobre esses assuntos como um cético talvez faria, mas considera que o resultado deles não é muito importante uma vez que o produto deles não é a virtude, não é o belo e o bom. Esses conhecimentos são para Sócrates conhecimentos triviais.

\section{Sabendo o que alguma coisa é}

Como vimos anteriormente Sócrates afirma não saber o que as virtudes são. Ele alegava que esse tipo de conhecimento, que leva à sabedoria, não pertence aos homens. Sabedoria essa, conceituada por Brickhouse and Smith como "um tipo de conhecimento que o seu possuidor é capaz de fazer o que é certo e julgar exemplos próprios pertinentes ao campo de trabalho em que é sábio." (BRICKHOUSE and SMITH, 1997, p.38) 
Mas se o Sócrates afirma não saber o que é a virtude, como pode ele falar sobre ela? Como acabamos de ver, Sócrates não afirma ser um sábio, uma vez que a sabedoria não pertence aos homens, mas em diversas passagens de seus diálogos ele afirma conhece-la. Como por exemplo, em uma passagem da Apologia (29b) onde ele afirma "saber que é mau e desrespeitoso fazer o errado e desobedecer o meu superior, independentemente de ser um deus ou um homem." (BRICKHOUSE and SMITH, 1997, p.35). Se ele não conhece a virtude, como isso é possível?

Segundo a interpretação defendida por Brickhouse and Smith, Sócrates tem um conhecimento, mas não possui um porque desse conhecimento. Em uma linguagem epistemológica mais contemporânea, arrisco dizer que Sócrates têm a proposição verdadeira mas não possui a sua devida justificação proposicional. Mas como isso é possível?

Brickhouse and Smith afirmam que um modo possível de se conhecer algo era a crença de que o conhecimento poderia vir pela via divinatória, e isso explicaria como Sócrates sabia as virtudes sem ao menos saber a justificação das mesmas. Ou seja, os deuses colocariam o conhecimento dentro de alguém. Esse argumento mostra-se um tanto quanto problemático uma vez que ele depende necessariamente da existência de deuses para ser verdadeiro, o que nos leva a um problema ontológico até hoje sem respostas.

Uma outra justificação dada pelos autores é o conhecimento das virtudes baseado nos exemplos do dia a dia, nas coisas triviais. As experiências nos mostram muitas coisas, mas não nos explicam o porque as coisas são desse modo, essa justificação de porque as coisas são assim não nos é revelada pela experiência, ela deve ser descoberta. Por isso é possível que Sócrates saiba o que é virtude através do dia a dia, sem saber explicar o que ela pode vir de fato a ser. Assim como é possível experimentar a chuva sem saber explica-la seria possível experimentar a virtude sem saber justifica-la.

Entretanto não é nem pela via divinatória e nem pela experiência cotidiana que Sócrates afirma ter sérias razões para defender que mais vale sofrer uma injustiça do que praticá-la. Mas sim pela via dos elenchos. Os elenchos são as refutações do argumento do adversário. Essas refutações não explicam o porquê, por exemplo, é melhor sofrer uma injustiça do praticar uma, mas levam o interlocutor a perceber que a sua tese "melhor praticar uma injustiça do que sofrer" está errada através de uma redução ao absurdo. Ou seja, não se explica porque é mais nobre sofrer uma injustiça do que praticá-la, mas se demonstra que é incoerente defender a posição que mais vale praticar uma injustiça do sofrê-la.

Os elenchos não demonstram então o que uma coisa é, mas demonstram que algo não possui relação com a coisa que é. Podemos não saber o que é ser justo, mas através dos elenchos, podemos demonstrar que o conceito de roubo não possui relação com o conceito de justiça, uma vez 
que o confronto entre esses dois termos como similares levaria necessariamente à uma contradição, a um absurdo. Podemos não saber o que é justo, mas saber que roubo não possui relação com o justo por si só é um progresso, é um avanço de conhecimento. Demonstra Sócrates então através dos elenchos que é possível dizer que "B" não é " $A$ " mesmo sem conhecermos o "A". Podemos dizer que o trabalho de Sócrates não é dizer o que uma coisa é, mas dizer que coisas não pertencem ao conceito dessa coisa investigada por Sócrates em questão.

\section{Burge e a noção de entendimento incompleto}

Vimos anteriormente a resposta de Brickhouse and Smith ao paradoxo Socrático, essa resposta, conforme mencionamos, passa pela divisão entre os tipos de conhecimento. O primeiro tipo de conhecimento é o conhecimento que os homens possuem acesso, que é segundo já mesmo mencionamos um conhecimento de pouco ou nenhum valor. $\mathrm{O}$ segundo tipo de conhecimento é o conhecimento que torna o seu possuidor sábio, que é o conhecimento das virtudes, do belo e do bom. Esse segundo tipo seria impossível ao homem conhecer, pois esse conhecimento seria o conhecimento exclusivo dos deuses. Além disso, vimos três modos possíveis para Sócrates chegar ao conhecimento das virtudes, ou perto delas. O primeiro modo era a via divinatória, o segundo modo era as experiências cotidianas e o terceiro e ultimo modo apresentado foi os elenchos Socráticos.

Nessa próxima parte do trabalho, desenvolveremos uma interpretação mais contemporânea a cerca dos conceitos para que possamos entender de um outro ponto de vista o que Sócrates que dizer quando se refere a não ter o conhecimento das virtudes e o que ele quer dizer quando diz possuir o conhecimento dos humanos. Nessa parte do trabalho usaremos da teoria de Tyler Burge sobre os conceitos, presentes no seu livro Foundations of mind. Onde demonstraremos que segundo esse autor é possível usarmos conceitos sem saber o seu significado exato.

$\mathrm{O}$ argumento central do texto Individualism and the mental (usaremos a abreviação IM) gira em torno de um experimento mental sobre significados dos conceitos, dividido por Burge em três partes. Reproduzido de maneira resumida abaixo:

Primeiro Passo: Suponhamos que uma dada pessoa tenha um grande numero de atitudes comumente atribuídas à palavra artrite. Por exemplo, essa pessoa acredita corretamente possuir artrite a anos, que a sua artrite nos punhos é mais dolorida que a artrite dos tornozelos, que é melhor ter artrite do que câncer e assim por diante. Em suma, essa dada pessoa possui diversas proposições usando esse termo em especifico. Em adição a todas essas proposições, essa pessoa também acredita que a sua artrite do tornozelo passou para a coxa. Essa pessoa, raciona, inteligente, competente 
linguisticamente, vai ao médico e expressa a ele a sua preocupação com a artrite ter passado para a coxa. O médico responde a ele que isso é possível uma vez que a artrite é uma doença exclusiva das juntas (uma inflamação das juntas) e portanto não pode ter subido para a coxa, e qualquer dicionário confirmaria isso. O paciente então se corrige e passa agora a perguntar o que será que ele tem na coxa.

Segundo Passo: Imaginemos agora uma situação contra factual onde essa mesma pessoa tem desde o nascimento até o relato médico a mesma história de eventos da situação descrita no passo 1 . As mesmas situações fisiológicas, as mesmas doenças, as mesmas situações físicas internas etc. O mesmo se aplica as expressões linguísticas e o modo de como ele aprendeu a palavra artrite. A diferença entre as duas situações está no seguinte fato: os médicos dessa situação contra factual, os lexicógrafos e os bem informados no assunto em geral, usam a palavra "artrite" para designar várias outras moléstias reumatoides - incluindo o uso desviante feito pela pessoa em questão que pensa que a sua artrite evoluiu para a coxa. Desse modo, na situação contra factual o termo artrite designa uma definição e extensão diferente do termo artrite do passo 1.

Terceiro Passo: O terceiro passo desse experimento mental é a interpretação do experimento (confrontando o passo 1 com o passo 2), onde Burge supõe que é razoável pensar o seguinte:

1 - Nas duas situações, tanto a real quanto a contra factual, o termo artrite possui significados diferentes.

2 - Esse significado diferente se deu não por uma diferenciação interna dos conteúdos mentais do sujeito, mas sim por uma mudança externa ao sujeito o que leva a conclusão que:

3 - Nenhum fenômeno mental do homem é insular.

Além disso, na seção IIc do IM, Burge ainda faz uma dedução importante resultante do experimento, segundo ele: “[...] $\mathrm{O}$ experimento mental aparenta depender da possibilidade de alguém ter uma atitude proposicional apesar de ter um entendimento incompleto de alguma parte do seu conteúdo" (BURGE, 2012, p.111). Durante a nossa comunicação, usamos de termos que muitas vezes não conhecemos o significado, e os tomamos para si como se soubéssemos o que eles significam e esses termos dão um valor de verdade proposicional na nossa argumentação. Essa ideia de que usamos termos sem entendê-los é o que chamaremos de entendimento incompleto ${ }^{3}$. Burge ao comentar sobre o experimento mental usa-se do termo artrite, mas isso é só um exemplo, segundo ele essa confusão conceitual é uma coisa que acontece com bastante frequência com outros tipos de termos ${ }^{4}$, de modo que isso é um problema que requer uma atenção especial. E é esse conceito em especifico de Burge que usaremos

\footnotetext{
3 Burge usa várias expressões para se referir ao entendimento incompleto, como por exemplo, misunderstanding, misconception entre outros. ${ }^{4} \mathrm{IIb}$.
} 
para apresentarmos uma outra interpretação do problema onde o termo em questão que gera a confusão não é artrite, mas sim virtudes.

\section{0 ponto que defendemos}

Brickhouse and Smith, como já vimos anteriormente, defendiam que Sócrates acreditava em dois tipos de conhecimento: o que faria o homem sábio e o que não faria o homem sábio. $O$ conhecimento que traria a sabedoria seria o conhecimento só possuído pelos deuses e o conhecimento que deixaria o seu possuidor sábio seria o conhecimento possuído pelos homens.

Defendemos neste artigo uma interpretação da epistemologia socrática onde usamos o conceito de Burge como referência para articularmos a teoria de que: Sócrates possivelmente sabia ou acreditava que era impossível ao homem ter um entendimento completo dos conceitos, e só quem poderia ter esse entendimento são os deuses. Aos homens restaria o reino do entendimento incompleto. Quando Sócrates dizia nada saber, proferindo assim a sua ignorância, ele na verdade, segundo nossa interpretação, estava tentando dizer que o conhecimento completo dos termos de uma frase é algo que só é possível aos Deuses, e não ao homem.

Defendemos que Sócrates ao dizer que não sabia o que era uma virtude ele talvez quisesse dizer "Eu não tenho o entendimento completo desse conceito e nenhum mortal poderá ter porque isso é impossível aos homens, o entendimento completo pertence aos Deuses." Sócrates, segundo nossa interpretação, tinha plena consciência de que era impossível aos homens ter esse tipo de conhecimento. E justamente por isso ele tinha tanta facilidade para desmontar o argumento daqueles que acreditavam tê-lo. Sócrates não se coloca em uma situação paradoxal porque ao dizer que sabe que não sabe na verdade não quer dizer que "não possui conhecimento", mas sim que possui o conhecimento incompleto, que para ele era de pouco ou nenhum valor, quase irrelevante.

\section{Considerações finais}

Foi discutida ao longo desse trabalho a ideia do paradoxo socrático, onde apresentamos o problema dentro da obra de Brickhouse and Smith. Vimos que a resolução desse aparente paradoxo foi feita através da distinção entre dois tipos de conhecimento, um que torna o seu possuidor sábio e outro que não torna seu possuidor sábio. Sócrates afirmava não saber de nada porque ele considerava que o conhecimento possuído por ele e pelos demais homens era um conhecimento que não tornava ninguém sábio. Segundo a interpretação de Brickhouse and Smith, Sócrates acreditava que o conhecimento real, o conhecimento das virtudes, o conhecimento que torna alguém sábio, era o conhecimento que somente os deuses tinham acesso e 
portanto quando ele dizia que nada sabia não existia incoerência nenhuma em seu pensamento.

Após essa apresentação da interpretação de Brickhouse and Smith sobre o problema, foi apresentado uma tentativa de uma nova interpretação do paradoxo, dessa vez escorado na teoria de entendimento incompleto, de Tyler Burge. Através do experimento mental descrito no artigo de Burge, conseguimos concluir que o significado dos termos não é uma coisa completa, ele é incompleto e vai se modificando ao longo do tempo baseado em fatores epistemológicos de cunho não insular, de modo que o significado não se da somente por uma diferenciação interna dos conteúdos mentais de um sujeito. Conforme foi demonstrado, os conteúdos mentais de um sujeito podem vir a variar de acordo com uma mudança no contexto onde esse sujeito está enquadrado.

Essa noção de entendimento incompleto, nos levou a uma interpretação alternativa do paradoxo socrático. Defendemos ao longo do artigo que quem sabe, Sócrates sabia que era impossível o entendimento completo de termos e que vivemos em um reino de entendimento incompleto. Sugerimos que Sócrates acreditava que o entendimento completo dos termos era algo que se fosse possível, era somente possível aos Deuses e não ao homem. Desse modo também arriscamos obter uma resposta ao paradoxo, quando Sócrates professa a sua ignorância ele se julga ignorante em assuntos que o homem jamais poderá resolver. Ele não diz que não possui nenhum conhecimento, mas sim que não possui conhecimento completo.

\section{Referências bibliográficas}

BENOIT, Hector. Socrates : o nascimento da razao negativa / 2. ed. Sao Paulo : Moderna, 1996

BURGE, Tyler. Foundations of mind. Oxford : Clarendon Press, 2012. , Origins of objectivity / Oxford : Clarendon Press, 2010.

, Truth, thought, reason : essays on Frege / Oxford : Clarendon

Press, 2010.

PLATÃO. Apologia de Sócrates / Rio de Janeiro Tecnoprint.

, A república : texto integral / São Paulo : Martin Claret , 2006.

, Diálogos : o banquete; Fedon; sofista; politico / 2. ed. Sao Paulo

Abril Cultural 1983.

Górgias / São Paulo : Fapesp, 2011.

Menon / 5. ed. Rio de Janeiro : Ed. PUC-Rio, 2009.

SANTOS. José Trindade. 1941-, Para ler Platão / São Paulo, SP : Loyola, c2008.

BRICKHOUSE, TH. C. \& N. D. SMITH, N. D. Plato's Socrates. New York: OUP, 1994. 